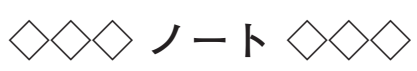

\title{
蛍光指紋によるサトイモの産地判別法開発
}

\author{
中村結花子 ${ }^{1}$, 藤田かお 抢 $^{2}$, 蔦 瑞樹 ${ }^{2, \dagger}$, 杉山純一 ${ }^{2}$, 粉川美踏 ${ }^{2}$,

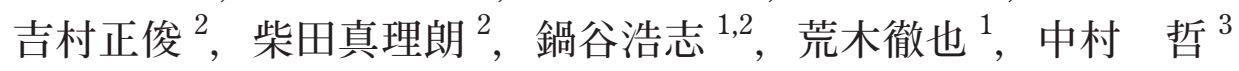 \\ 1 東京大学大学院農学生命科学研究科, \\ 2 独立行政法人農業・食品産業技術総合研究機構食品総合研究所 \\ 3 独立行政法人農林水産消費安全技術センター本部
}

\section{Development of a Method for Determination of the Geographic Origin of Taros Using Fluorescence Fingerprint}

\author{
Yukako NAKAMURA ${ }^{1}$, Kaori FUJITA ${ }^{2}$, Mizuki TSUTA ${ }^{2, \dagger}$, Junichi SUGIYAMA $^{2}$, \\ Mito KOKAWA ${ }^{2}$, Masatoshi YOSHIMURA ${ }^{2}$, Mario SHIBATA ${ }^{2}$, \\ Hiroshi NABETANI ${ }^{1,2}$, Tetsuya ARAKI ${ }^{1}$, and Satoru NAKAMURA ${ }^{3}$ \\ ${ }^{1}$ Graduate School of Agricultural and Life Sciences, The University of Tokyo, \\ 1-1-1 Yayoi, Bunkyo-ku, Tokyo 113-8657, Japan \\ ${ }^{2}$ National Food Research Institute, National Agriculture and Food Research Organization, \\ 2-1-12 Kan-nondai, Tsukuba-shi, Ibaraki 305-8642, Japan \\ ${ }^{3}$ Headquarters, Food and Agricultural Materials Inspection Center, Saitama Shintoshin National Government Building, \\ Kensato Building 2-1, Shintoshin, Chuo-ku, Saitama-shi, Saitama 330-9731, Japan
}

\begin{abstract}
Fluorescence fingerprints (FF) of 137 Japanese taro samples and 23 Chinese ones, harvested in 2008, were measured in the excitation and emission wavelengths ranging from 200 to $900 \mathrm{~nm}$ at 10 $\mathrm{nm}$ intervals after grinding and homogenization. The obtained data set was split into calibration and validation data sets. Canonical discriminant analysis was applied to the former to develop a model for the prediction of the country of origin from its FF. Then the model was applied to the validation set to test the model accuracy, which resulted in the misclassification rate of $9.4 \%$. The area under the curve (AUC) of the receiver operating characteristics for the FF method was equivalent to those for inorganic elements composition and the combination of inorganic elements composition and the $\mathrm{Sr}$ isotopic ratio. These results showed the potential of $\mathrm{FF}$ as a quick and accurate method to determine the geographic origin of taros.
\end{abstract}

Keywords: excitation-emission matrix, multivariate analysis, non-destructive measurement, false labeling

\section{1. 緒言}

日本では 2000 年から JAS 法によりすべての農産物に 対する原産地表示が義務付けられている。 中でもサト イモ（Colocasia esculenta（L.）Schott）は，見た目の 違いが産地間で小さく，流通時期などのすみわけがで きていないという理由から，1996 年に産地表示義務が 課せられた青果物 5 品目のうちの 1 つである [1]. 日本

(受付 2013 年 4 月 15 日, 受理 2013 年 5 月 27 日)

₹305-8642 茨城県つくば市観音台2-1-12

FAX: 029-839-1552, E-mail: mizukit@affrc.go.jp
へのサトイモの輸入は中国からのものが多く, 2011 年 では日本産の単価 $(544$ 円 $/ \mathrm{kg}$ ) が中国産の単価 $(281$ 円 $/ \mathrm{kg}$ ) の約 2 倍 [2] と価格差が大きい，そのために中 国産に対して国産と表示する産地偽装が頻発している. そこで偽装の抑止力として, 科学的根拠に基づく産地 判別技術が求められている.

現在サトイモの産地判別技術として, 複数の微量元 素濃度分析 [3,4] や安定同位体比分析 [5]による手法が 試みられて打り，前者に打いては，日本産サンプルに 対して 100\%，中国産サンプルに対して $93.75 \%$ という高 い判別率が得られている. しかしこれらの分析手法に は, 時間のかかる煩雑な前処理や, 高価な分析機器, 
専門的な知識と技術が必要となる。したがって多くの サンプルの分析を行うような実用的な技術としては不 十分であるといえる，このため，実用的に用いること ができる迅速で簡便な新たな手法が必要とされている。

蛍光指紋は試料に照射する励起波長，試料から発せら れる蛍光波長，そしてその蛍光強度の 3 軸からなる 3 次 元データである. 連続的に変化させた複数の励起波長に 対する蛍光スペクトルを順に並べることで得られる．各 物質に固有の形状パターンを示し，一般的な蛍光分析に 比べ情報量が多いという特徵がある。さらに非破壊か つ非接触で迅速な計測が可能である。これまでにワイ ンの醸造所や醸造年の判別 [6] やエビの産地や品種判別 [7]への適用例が報告されている. また, 著者らはマン ゴーを試料とした場合に果皮の蛍光指紋を計測するこ とで産地判別の可能性があるという報告を行っている [8]. 一方でサトイモのように塊茎や地下茥を食用に用

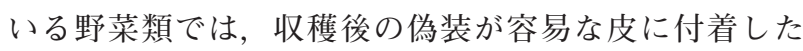
土壌の影響を避け, 可食部を計測する必要がある。

本研究の目的は，蛍光指紋によるサトイモの産地判 別の可能性を明らかにすることである. 加えて, 従来 法である元素濃度および同位体比分析との判別精度の 比較を行った.

\section{2. 実験}

\section{1 試料}

2008 年度に生産された生鮮サトイモを用いた。日本 産は直売所にて生産者の氏名打よび生産地を確認の上 44 都府県から 117 サンプル入手し，海外産として中国 産の 23 サンプルを小売店, 卸・仲卸業者から入手した. 次に調製方法を示す。前処理として，試料を購入後に まず皮をむき，ポリ袋に入れてハンマーでつぶしてか ら冷凍保存した。そして計測条件をそろえるために, 計測直前に $1 \sim 2 \mathrm{~g}$ 程度をサンプリングしてから，マル チビーズショッカー (MB601, 安井器械(株)) を用い て $2000 \mathrm{rpm}$ で 40 秒間の粉砕を行い, 試料を均質化した. その後, 試料の一部を測定機器に付属の粉末試料セル
に封入した。 1 サンプルにつき封入と蛍光指紋計測を 2 回繰り返した.

\section{2 蛍光指紋計測}

分光蛍光光度計 (F7000，（株）日立ハイテクノロジー ズ）を使用した。計測範囲は励起波長・䖢光波長ともに， 機器で計測可能な全範囲である $200 \mathrm{~nm}$ から $900 \mathrm{~nm}$ と した。波長間隔は両者とも $10 \mathrm{~nm}$ とした。また，ホ卜 マル電圧は $400 \mathrm{~V}$, スキャンスピードは $30,000 \mathrm{~nm} /$ min, レスポンスは $0.002 \mathrm{~s}$ に設定した.

\section{3 データの前処理}

Fig. 1 にデータの前処理工程を示す. 蛍光指紋には蛍 光由来ではないデータも含まれる．そのため蛍光波長 $<$ 励起波長となる条件下にあるデータと, 散乱光として蛍 光波長 $=$ 励起波長 $\pm 20 \mathrm{~nm}$ 幅，二次光として蛍光波長 $=$ 励起波長 $\times 2 \pm 30 \mathrm{~nm}$ 幅, 三次光として蛍光波長 $=$ 励起 波長 $\times 3 \pm 30 \mathrm{~nm}$ 幅, 四次光として蛍光波長 $=$ 励起波長 $\times$ $4 \pm 40 \mathrm{~nm}$ 幅の条件下にあるデータを消去した [8].

(励起波長) ・ (蛍光波長) を 1 つの（波長条件）とし て考え，データを並べ替えることで二次元行列データ から一次元べクトルデータへと蛍光指紋を展開した.

\section{4 統計解析}

統計ソフト JMP9（SAS Institute Japan 株式会社）を 用いて，蛍光指紋，つまり各波長条件における蛍光強 度を説明変数とし，産地を目的変数として，正準判別 分析を行った。正準判別分析では，説明変数の線形結 合により，各サンプルの所属グループを推定する正準 判別関数を作成する. 線形結合の係数は, 説明变数が 構成する多次元空間におけるグループ間変動とグルー プ内変動の比が最大になるように定められ，各サンプ ルの正準判別関数の出力は正準得点とよばれる. 判別 すべき 2 つのグループ $\mathrm{G}_{1}, \mathrm{G}_{2}$ における正準得点の平均 值を $\mathrm{m}_{1}, \mathrm{~m}_{2}$ としたとき，両者の中点が判別境界とし て用いられる.すなわち，あるサンプルの正準得点が 判別境界を超えるかどうかによって，そのサンプルが

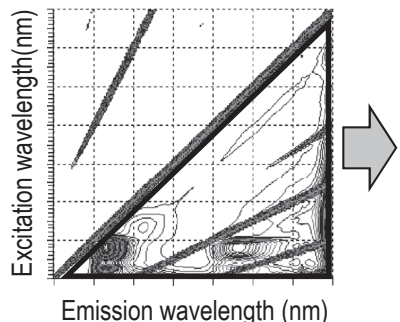

FF

(5041 wavelength condition)

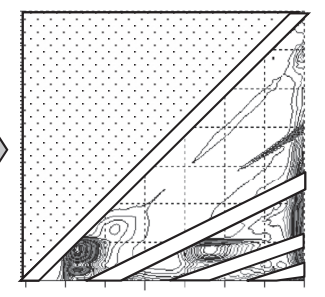

Removing non-fluorescent data and scattered light

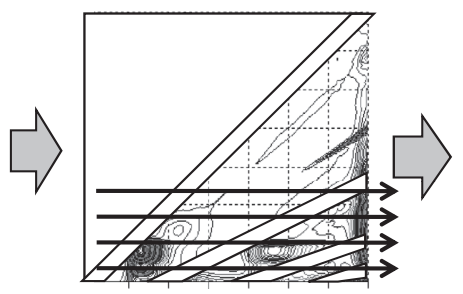

Ex.200/Em.230nm Ex.200/Em.240nm Ex.200/Em.250nm Ex.200/Em.260nm

$$
\begin{aligned}
& \text { Sorting to } \\
& \text { a row vector }
\end{aligned}
$$

Fluorescence intensity (2063 wavelength condition)

Fig. 1 Preprocessing the fluorescence fingerprint (FF) data. 
$\mathrm{G}_{1}, \mathrm{G}_{2}$ のどちらに所属するかを判定する.

解析に拈いては全データを，キャリブレーションセッ トとバリデーションセットの 2 グループに折半して分 析に供した。 まずキャリブレーションデータセットを 用いて正準判別関数を作成した。この際に変数選択を 行い，多くの波長条件の中から判別に有用な波長条件 のみを抽出した。正準判別関数はキャリブレーション セットに合わせて作られるので，オーバーフィッティ ングにより他のサンプル群には適用できない基準が作 られる可能性がある。そこで，バリデーションデータ セットに作成した正準判別関数をあてはめて，判別基 準としての有効性を検証した，有効性の指標として䛊 判別率を用いた。誤判別率とは，正準判別関数によっ て実際の産地とは異なる産地として判別されたサンプ ルの割合を示す。

変数選択では，ステップワイズ変数選択により $\mathrm{F}$ 值 の大きいものから順に正準判別関数に取り込み，F值 の最大のものとの比が $1 / 10$ 以下である場合には取り込 まなかった [9]. 正準判別関数を変更するたびに $\mathrm{F}$ 值は 変化するため，すでに正準判別関数に取り込まれた変 量のうち $\mathrm{F}$ 值が最大のものの 1/10 以下になった場合は 正準判別関数から除外した.

\section{5 従来法との判別精度比較}

蛍光指紋による産地判別の精度を検証するため，同 一サンプルを用いて行われた微量元素濃度 $[3,4]$ および $\mathrm{Sr}$ 同位体比 [5] の従来法による産地判別結果と判別精 度を比較した。前者では誘導結合プラズマ発光分析法 および誘導結合プラズマ質量分析法にて $\mathrm{Na}, \mathrm{Mg}, \mathrm{P}$, $\mathrm{Ca}, \mathrm{Mn}, \mathrm{Fe}, \mathrm{Ni}, \mathrm{Cu}, \mathrm{Zn}, \mathrm{Rb}, \mathrm{Sr}, \mathrm{Cd}$ 及び $\mathrm{Ba}$ の計 13 元素の定量を行い，後者では多重検出器型 ICP 質量 分析計を用いて ${ }^{87} \mathrm{Sr} /{ }^{86} \mathrm{Sr}$ を測定した。得られた測定值 を説明変数，産地を目的変数とした正準判別分析を行
い，微量元素分析のみ，または微量元素分析と $\mathrm{Sr}$ 同位 体比の測定值両方を用いた正準判別関数を作成した.

蛍光指紋と従来法の判別精度を比較するため, Receiver Operating Characteristic（ROC）曲線 [10] を 求めた。 ROC 曲線とは判別得点の閾值を変えながら横 軸に偽陽性率，縦軸に感度をとってプロットしたもの である。偽陽性率とは陰性試料のうち誤判別される割 合，感度とは陽性試料のうち正しく判別される割合を 示す. 判別精度の指標として ROC 曲線の下の面積, Area Under the Curve（AUC）を用いた. AUCは 0 か ら 1 までの值をとり, 完全に分類できている場合には 1 , ランダムな分類の場合には 0.5 となる。つまり AUC が 1 に近いほど判別精度が良いことを示す. 陽性を中国産, 陰性を日本産として ROC 曲線と AUC を求め, 蛍光指紋, 微量元素分析のみ，及び微量元素分析と $\mathrm{Sr}$ 同位体を組 み合わせた判別結果の比較を行った。

\section{3. 結果および考察}

合計 280 個の蛍光指紋データが得られた. Fig. 2 に得 られた日本産打よび中国産サトイモの蛍光指紋データ の一例を示す。両者には励起波長 $280 \mathrm{~nm}$ ・蛍光波長 $350 \mathrm{~nm}$ 近傍打よび励起波長 $320 \mathrm{~nm}$ ・蛍光波長 $400 \mathrm{~nm}$ 近傍に共通した蛍光ピークが確認され，これらはトリ プトファンおよびビタミン B 6 によるものと考えられた [11].しかしながら産地ごとに特徴的なピークはみら れなかった。つまり蛍光指紋の目視による判別は困難 と考えられる.

次に，判別分析の結果を示す. 変数選択により，3つの 波長条件下での蛍光強度が選ばれ，正準判別関数 $D F$ と してそれらの線形結合による式が以下のように作られた。

$$
\begin{aligned}
& D F=-1.50 \times 10^{-2} \times I(220,580)-2.39 \times 10^{-2} \times \\
& I(340,420)+2.57 \times 10^{-3} \times I(380,890)
\end{aligned}
$$
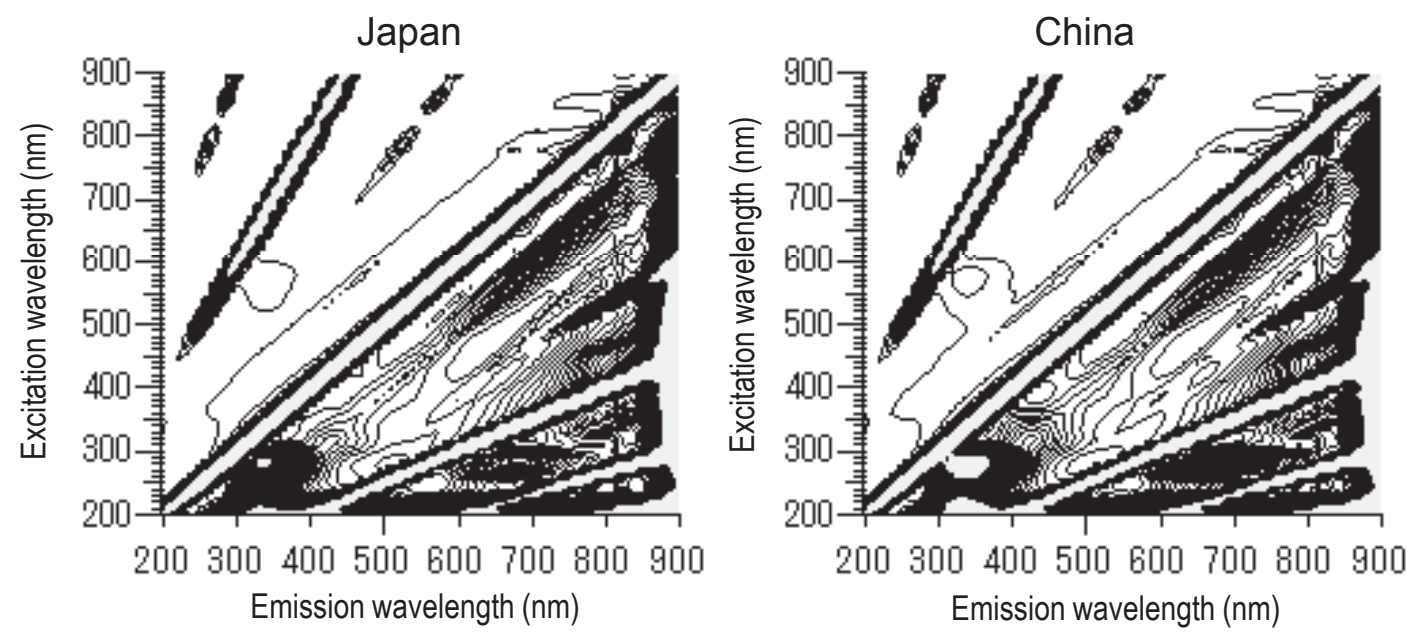

Fig. 2 FF contour maps of taros. 


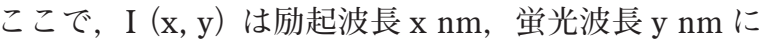
打ける蛍光強度を示す. Fig. 3 にこのときの正準得点プ ロットを示す。このプロット図はサンプル間の違いを 視覚的に表したものである。横軸の正準得点 1 が正準 判別関数から算出された值で，判別境界は正準得点 $=$ 1.37 であった。

Table 1 に分類表を示す．誤判別率はキャリブレー ションセットでは $6.3 \%$, バリデーションセットでは $9.4 \%$ となった，誤判別率から，蛍光指紋データから作られ た正準判別関数によって十分にサトイモの産地を判別 することが可能であることが明らかになった.

一方でこのとき，キャリブレーションセットでは偽 陽性率は $4.3 \%$ ，感度は $84.6 \%$ で，バリデーションセッ
トではそれぞれ 7.6\%，80.0\%であった。実用的に用いる 場合，偽陽性率を低く抑える，あるいは陽性サンプル の検出を優先するなど，目的に合わせて判別境界を変 更し，擬陽性率执よび感度を調整することができる。

Fig. 4 にキャリブレーションとバリデーションの ROC 曲線を示す．AUC はそれぞれ $0.973,0.952$ だった。 一方，微量元素濃度のみによる場合の AUC は 0.952 , 微量元素濃度および $\mathrm{Sr}$ 同位体比の組み合わせによる場 合は 0.982 だった。これら $2 つ の A U C$ はサンプル群に Leave-one-out cross validation (LOOCV) を適用して 得られた判別基準の值である. 以上の数值から，蛍光 指紋は微量元素濃度のみ，または微量元素濃度打よび $\mathrm{Sr}$ 安定同位体比分析と同等の判別能力をもつことが示 (a) Calibration

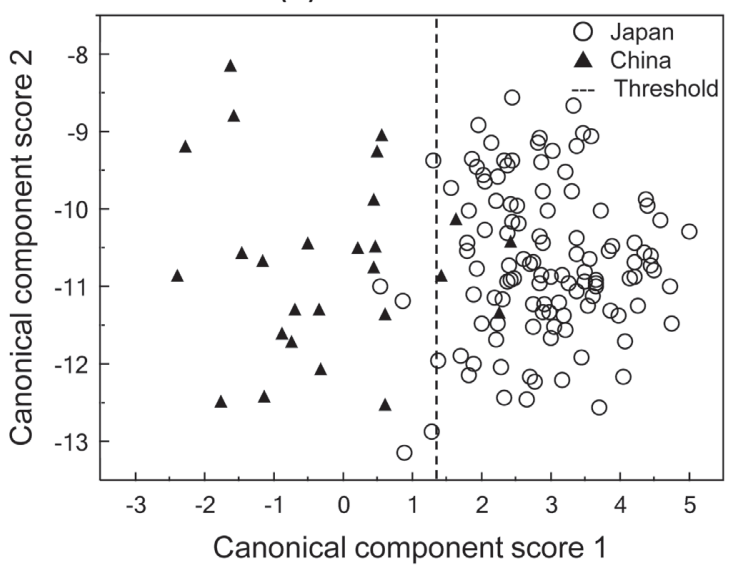

(b) Validation

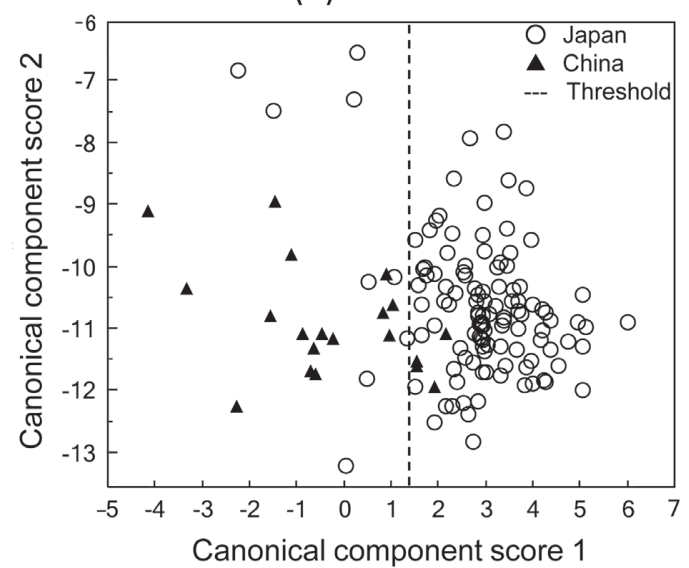

Fig. 3 Canonical component score plot.

Table1 Confusion matrix.

(a) Calibration

\begin{tabular}{ccc}
\hline \multirow{2}{*}{ Actual origin } & \multicolumn{2}{c}{ Predicted origin } \\
\cline { 2 - 3 } & China & Japan \\
\hline China & 22 & 4 \\
\hline Japan & 5 & 111 \\
\hline
\end{tabular}

(a) Calibration

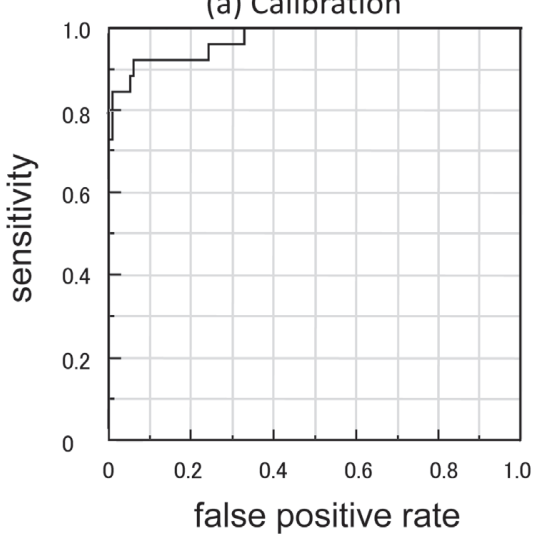

(b) Validation

\begin{tabular}{ccc}
\hline \multirow{2}{*}{ Actual origin } & \multicolumn{2}{c}{ Predicted origin } \\
\cline { 2 - 3 } & China & Japan \\
\hline China & 16 & 4 \\
\hline Japan & 9 & 109 \\
\hline
\end{tabular}

(b) Validation

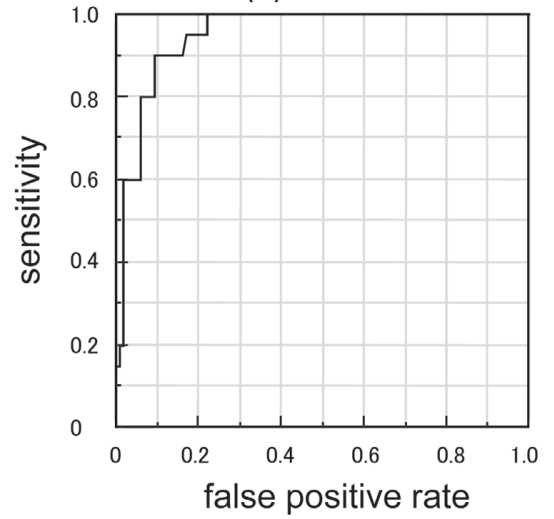

Fig. 4 ROC curve. 
された. また今後の解析の際に蛍光指紋データとこれ らの分析データと組み合わせ，情報量を増大させるこ とにより判別精度向上の可能性が考えられる.

以上のことから，正準判別関数に採用された $3 つ の$ 波長条件下に打ける蛍光強度は，産地間の違いをよく 表すことがわかった。また今回の計測時間は，1つの蛍 光指紋として 5041 波長条件を計測するため約 4 分を要 したが，3波長条件のみを計測すればよいということに なれば短縮が期待される.

\section{4. 結 論}

サトイモを試料とした場合に蛍光指紋による産地判 別が十分に可能であることを示した。 また本手法で得 られた正準判別関数が微量元素濃度および安定同位体 比によるものと同等の判別能力をもつことが示された. 前処理の手順の簡便さや計測時間の短さを考慮すると， 蛍光指紋は実用的なスクリーニング手法として有効で あると考えられる。また，今後の課題として生鮮のも のだけでなく冷凍のサトイモについても適用できる正 準判別関数を求めることが挙げられる.

\section{5. 謝辞}

$\mathrm{Sr}$ 同位体比のデータをご提供いただきました農業環 境技術研究所の川崎晃博士に御礼申し上げます。本研 究は農林水産省委託プロジェクト「食品・農産物の表 示の信頼性確保と機能性解析のための基盤技術の開発」 により実施しました。また，JSPS 科研費 萌芽研究 24658220 の助成を受けたものです。ここに謝意を表し ます。

\section{6. 参 考 文 献}

1) T. Ueki; "Food Labeling and Authentification Technology" (in Japanese), J. Jpn. Soc. Food Sci. Technol, 55, 405-409 (2008).

2) Ministry of Agriculture, Forestry and Fisheries; 2011 Report of Survey on Trend of Price and Sales of Perishable Food (2012).

3) N. I. Kobayashi, K. Tanoi, A. Hirose, T. Saito, A. Noda, N. Iwata, A. Nakano, S. Nakamura, T. M. Nakanishi; Analysis of the Mineral Composition of Taro for Determination of Geographic Origin, J. Agric. Food Chem., 59, 4412-4417 (2011).

4) S. Nakamura, T. Suzuki, H. Horita, A. Nakano; Detection of Falsely Labeled Taro in Japan by Elemental Analysis: Improvement of Disrimination Ability Using a Sampling Plan,
Food Sci. Technol. Res., 18, 723-733 (2012).

5) S. Nakamura, A. Kawasaki, T. Hirata; "Research Results Book No. 492: Integrated research program for functionality and safety of food toward an establishment of healthy diet”, Agriculture, Forestry and Fisheries Research Council ed., Agriculture, Forestry and Fisheries Research Council, 2013, pp. $36-42$.

6) C. Yin, H. Li, C. Ding, H. Wang; Preliminary Investigation on Variety, Brewery and Vintage of Wines using Threedimensional Fluorescence Spectroscopy, Food Sci. Technol. Res., 15, 27-38 (2009).

7) J. K. Eaton, A. Alcivar-Warren, J. E. Kenny; Multidimensional Fluorescence Fingerprinting for Classification of Shrimp by Location and Species. Environ. Sci. Technol. 46, 2276-2282 (2012).

8) Y. Nakamura, K. Fujita, J. Sugiyama, M. Tsuta, M. Shibata, M. Yoshimura, M. Kokawa, H. Nabetani, T. Araki; "Discrimination of the Geographic Origin of Mangoes Using Fluorescence Fingerprint” (in Japanese), J. Jpn. Soc. Food Sci. Technol, 59, 387-393 (2012).

9) M. Hirono, T. Hayashi; "Method to Utilize Multivariate Data by JMP (JMP Niyoru Tahenryo Deta Katsuyoujutu)", Kaibundo, Tokyo, Japan, 2004, p.177.

10) D. Bamber; The Area above the Ordinal Dominance Graph and the Area below the Receiver Operating Characteristic Graph, J. of Mathematical Psychology, 12, 387-415 (1975).

11) J. Christensen, L. Norgaard, R. Bro, S. B. Engelsen; Multivariate autofluorescence of intact food systems. Chemical Reviews-Columbus, 106, 1979-1994 (2006).

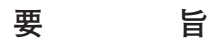

2008 年産の日本産サトイモ 117 個，2008 年産の中国 産サトイモ 23 個を粉砕、均一化したのち、それらの蛍 光指紋を励起，蛍光波長範囲 200-900 nm に打いて，10 $\mathrm{nm}$ おきに計測した。得られたデータはキャリブレー ションとバリデーションセットに二分した。前者に正 準判別分析を適用し，サトイモの産地を判別するモデ ルを構築した。得られたモデルをバリデーションセッ トに適用したところ，誤判別率は $9.4 \%$ となった。 Receiver Operating Characteristic (ROC) 曲線の下の 面積である Area Under the Curve (AUC) を蛍光指紋 法について求めたところ，微量元素濃度のみ扎よび微 量元素濃度と $\mathrm{Sr}$ 安定同位体比の組み合わせによる既往 の産地判別法と同等の值を示した.これらの結果から， 蛍光指紋による迅速かつ高精度なサトイモの産地判別 の可能性が示された。 